\title{
Escarificação química da semente para favorecer a emergência e o crescimento do porta-enxerto Trifoliata
}

\author{
Roberto Pedroso de Oliveira( ${ }^{(1)}$, Walkyria Bueno Scivittaro ${ }^{(1)}$ e Elizete Beatriz Radmann(2)
}

(1)Embrapa Clima Temperado, Caixa Postal 403, CEP 96001-970 Pelotas, RS. E-mail: rpedroso@cpact.embrapa.br, wbscivit@cpact.embrapa.br
(2)Universidade Federal de Pelotas, Caixa Postal 354, CEP 96001-970 Pelotas, RS. E-mail: eradmann@gmail.com

Resumo - O objetivo deste trabalho foi avaliar a emergência e o crescimento de plantas do porta-enxerto de citros Trifoliata [Poncirus trifoliata (L.) Raf.], provenientes de sementes escarificadas quimicamente. A semeadura foi realizada em tubetes de plástico, contendo substrato comercial, em viveiro-telado. Foram utilizados: tratamento químico de referência - TQR (imersão por 45 minutos em solução 0,5 L NaClO 12\%, 3 mL HCl e 20 g NaOH diluídos para 2 L de água); metade, o dobro e quatro vezes a concentração do TQR; metade e o dobro do tempo de imersão do TQR; omissão de $\mathrm{NaClO}$; omissão de $\mathrm{HCl}$; omissão de $\mathrm{NaOH}$; tratamentos- controle utilizando sementes com tegumento e sem tegumento. Utilizou-se delineamento de blocos ao acaso, com quatro repetições e unidades experimentais constituídas por 42 tubetes contendo uma semente cada. A emergência das plantas de Trifoliata ocorre do 6o ao 45ํㅡㄹ dia depois da semeadura. A porcentagem final de emergência varia de 92,4 a 99,7\%. Aos 65 dias da semeadura, as sementes submetidas à escarificação no tratamento com o dobro da concentração do TQR resultam em porta-enxertos com maior produção de matéria seca total ( 0,52 g por planta) e bom desempenho quanto à média de altura $(15,2 \mathrm{~cm})$ e diâmetro do caule $(2,41 \mathrm{~mm})$.

Termos para indexação: Poncirus trifoliata, citros, plântulas, tegumento, hipoclorito de sódio.

\section{Seedcoat chemist scarification to optimize the emergency and growth of Trifoliata rootstock}

\begin{abstract}
The aim of this work was to evaluate the emergency and growth of the Trifoliata [Poncirus trifoliata (L.) Raf.] citrus rootstock, derived from chemically scarified seeds. The sowing was carried through in plastic dibble tubes, containing commercial substrate, in a greenhouse. The treatments consisted of chemical reference treatment of the seeds - TQR (45-minute immersion in solution composed of $0.5 \mathrm{~L} \mathrm{NaClO} 12 \%, 3 \mathrm{~mL} \mathrm{HCl}$ and $20 \mathrm{~g} \mathrm{NaOH}$ diluted in $2 \mathrm{~L}$ of water); half, double and four times TQR concentration; half and double immersion time of TQR; omission of $\mathrm{NaClO}$; omission of $\mathrm{HCl}$; omission of $\mathrm{NaOH}$; control treatments comprising seeds with tegument and without tegument. The experiment was a randomized complete block design, with four replications and experimental units composed of 42 dibble tubes comprising one seed each. The emergence of Trifoliata seedlings occurred during the $6^{\text {th }}$ to $45^{\text {th }}$ day after sowing. Final percentage of emergence varies from 92.4 to 99.7\%. Sixty five days after sowing, seeds submitted to the double concentration of TQR result in rootstocks with higher total dry matter (0.52 g per plant), and good height $(15.2 \mathrm{~cm})$ and shoot diameter $(2.41 \mathrm{~mm})$.
\end{abstract}

Index terms: Poncirus trifoliata, citrus, seedlings, tegument, sodium hypochlorite.

\section{Introdução}

O Brasil é o maior produtor mundial de citros, com mais de 250 milhões de árvores, produzindo cerca de 20 milhões de toneladas de fruta por ano (Anuário..., 2005). No entanto, ainda precisa evoluir muito no que tange ao aspecto qualidade de frutas produzidas, principalmente para conquistar o mercado internacional de frutas frescas.
As pragas são uma das principais ameaças à citricultura nacional (Laranjeira et al., 2005). Para minimizar sua ocorrência e disseminação, estados como São Paulo, Minas Gerais e Rio Grande do Sul estão exigindo que as mudas de citros sejam produzidas em ambiente protegido, utilizando substrato, sementes e borbulhas isentos de patógenos (Oliveira \& Scivittaro, 2003). 
Mudas certificadas apresentam melhor qualidade genética, fitossanitária e fitotécnica, justificando seu uso, embora o custo desse tipo de muda seja significativamente maior do que o das produzidas em campo (Oliveira \& Scivittaro, 2004). Conseqüentemente, pesquisas necessitam ser implementadas a fim de otimizar o sistema de produção de mudas. Em virtude do custo das sementes e da estrutura do ambiente protegido, um desses pontos relevantes refere-se à obtenção de altas taxas de germinação e uniformidade de desenvolvimento das plantas (Oliveira \& Scivittaro, 2003).

O processo de germinação dos porta-enxertos de citros é, normalmente, lento, principalmente quando se utiliza o Trifoliata [Poncirus trifoliata (L.) Raf.] em condições de temperaturas amenas (Rouse, 1997). O Trifoliata tem sido o principal porta-enxerto de citros utilizado no Rio Grande do Sul, principalmente por ser tolerante ao frio e proporcionar alta qualidade à fruta (Oliveira \& Scivittaro, 2003). No entanto, suas sementes são recalcitrantes, perdendo rapidamente a viabilidade durante o armazenamento, e seu tegumento é mais coriáceo do que o dos demais porta-enxertos de citros, dificultando a embebição e favorecendo a podridão das sementes durante a germinação (Oliveira et al., 2003).

Vários autores têm sugerido a existência de algum tipo de dormência em sementes de Trifoliata e que a dormência está relacionada ao fato de o tegumento atuar como barreira física à embebição de água ou à difusão de gases, ou ainda pela presença, no tegumento, de algum inibidor de desenvolvimento do embrião (Soetisna et al., 1985). Para aumentar a taxa de germinação e a uniformidade de emergência das plantas, podem ser utilizados diversos tratamentos do tegumento das sementes, tais como escarificação física com água a diferentes temperaturas, calor seco, calor úmido, frio seco ou radiação; escarificação química com soluções ácidas, enzimas ou solventes orgânicos e substâncias estimuladoras da germinação, como nitrato de potássio ou reguladores de crescimento (Radhamani et al., 1991). Embora o assunto seja bastante discutido quanto às sementes de plantas daninhas, leguminosas $\mathrm{e}$ forrageiras (Araújo et al., 2000), pouco se conhece sobre a eficiência de tratamentos de sementes de Trifoliata e seu nível de aplicação no setor produtivo.

O objetivo deste trabalho foi avaliar a emergência e o desenvolvimento de plantas do porta-enxerto de citros Trifoliata, provenientes de sementes escarificadas quimicamente.

\section{Material e Métodos}

O experimento foi realizado sob condições de viveirotelado, na Embrapa Clima Temperado, em Pelotas, RS.
Utilizaram-se sementes certificadas de Trifoliata, seleção Davis A, extraídas de frutos maduros provenientes de plantas matrizes da Embrapa Clima Temperado.

A remoção da mucilagem das sementes foi realizada manualmente, em água corrente, sobre uma peneira. As sementes foram secadas à sombra, sobre papel toalha, por 72 horas, sendo armazenadas em câmara fria a $4^{\circ} \mathrm{C}$ e umidade relativa do ar de $70 \%$, por 210 dias.

A semeadura foi realizada em meados de outubro de 2004, em tubetes de plástico cônicos, com capacidade para $50 \mathrm{~cm}^{3}$. Os tubetes foram preenchidos com substrato comercial, específico para mudas de citros (Multiplanta Citros), adubado com 3,5 $\mathrm{kg} \mathrm{m}^{-3}$ do fertilizante de liberação lenta Osmocote, fórmula 15-10-10 (Oliveira \& Scivittaro, 2003), e foram dispostos em bandejas metálicas com capacidade para 192 tubetes.

Foram avaliados 11 tratamentos, sendo: tratamento químico de referência (TQR), que consistiu na imersão de 200 g de sementes, sob agitação por 45 minutos, em solução composta por 0,5 L de hipoclorito de sódio ( $\mathrm{NaClO})$ a 12\%, $3 \mathrm{~mL}$ de ácido muriático $(\mathrm{HCl})$ e $20 \mathrm{~g}$ de hidróxido de sódio comercial $(\mathrm{NaOH})$, diluídos para $2 \mathrm{~L}$ de água, com posterior lavagem em água corrente e remoção do tegumento, esfregando-se as sementes umas sobre as outras, no interior de um pano úmido; metade da concentração do TQR; dobro da concentração do TQR; quatro vezes a concentração do TQR; metade do tempo de imersão no TQR; dobro do tempo de imersão no TQR; omissão de hipoclorito de sódio do TQR; omissão de ácido muriático do TQR; omissão de hidróxido de sódio do TQR; tratamento-controle, utilizando sementes com tegumento; e tratamentocontrole utilizando sementes manualmente descascadas. Utilizou-se delineamento de blocos ao acaso, com quatro repetições, e as unidades experimentais foram constituídas por 42 tubetes contendo uma semente cada.

A porcentagem de emergência foi avaliada, a cada cinco dias, durante 50 dias, considerando-se todas as plantas de cada parcela. Depois de 65 dias, foram avaliadas a altura de todas as plantas de cada parcela e o diâmetro do caule, medido $1 \mathrm{~cm}$ acima do colo das plantas. Nessa ocasião, avaliaram-se, também, as produções de matéria seca das raízes, da parte aérea e total, considerando-se oito plantas por parcela. Na análise estatística da variável porcentagem de plantas emergidas, selecionaram-se três épocas de avaliação, abrangendo desde o início até o final do processo germinativo (15, 30 e 45 dias depois da semeadura). Os dados foram submetidos à análise de variância, comparando-se as médias dos tratamentos pelo teste de Tukey $(\mathrm{p}<0,05)$. Os dados referentes à porcentagem de plantas emergidas foram transformados para arc sen $(\mathrm{x} / 100)^{0,5}$. 


\section{Resultados e Discussão}

A emergência das plantas de Trifoliata ocorreu do $6^{0}$ ao 45 을 dia depois da semeadura, concentrando-se no período compreendido entre o $6^{\circ}$ e o $30^{\circ}$ dia (Figuras 1, 2 e 3 ). As porcentagens finais de emergência foram superiores a 88,7\%, variando de acordo com o tratamento (Tabela 1).

A germinação de porta-enxertos de citros é lenta (Soetisna et al., 1985), havendo diferenças de acordo com a espécie e as condições de cultivo (Radhamani et al., 1991). Este trabalho foi realizado no interior de viveiro-telado, utilizando substrato comercial e irrigação controlada, sendo a semeadura realizada em um período com temperatura média mínima de $20,5^{\circ} \mathrm{C}$ e máxima de $30,4^{\circ} \mathrm{C}$. Desta forma, as condições locais foram bastante favoráveis à germinação, justificando a sua velocidade. Conforme Rouse (1997), a temperatura é

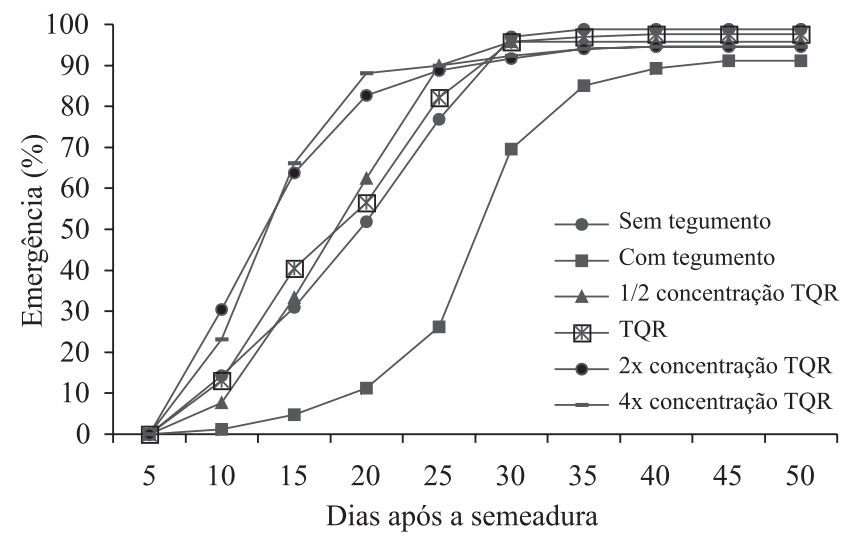

Figura 1. Emergência de plantas da Trifoliata (Poncirus trifoliata) depois da semeadura, decorrente da concentração do tratamento químico da semente.

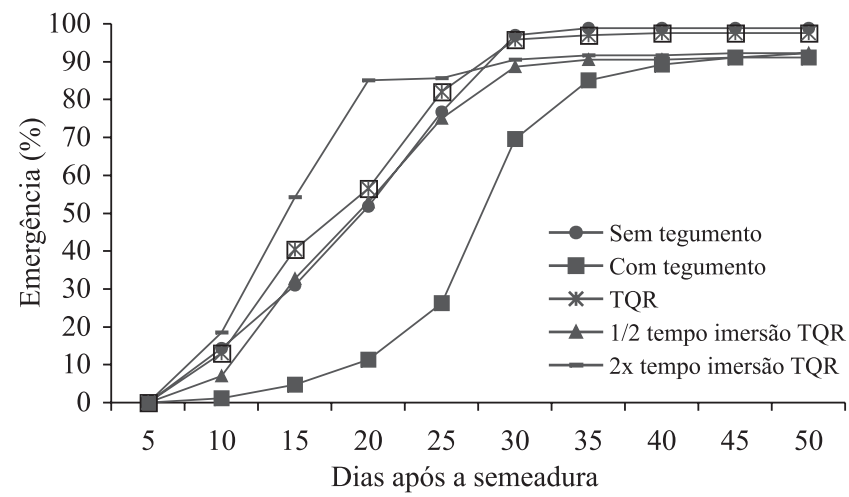

Figura 2. Emergência de plantas de Trifoliata (Poncirus trifoliata) depois da semeadura, decorrente do tempo de imersão das sementes no tratamento químico. um dos fatores de maior relevância no processo de germinação, sendo $25^{\circ} \mathrm{C}$ a ideal para germinação de sementes de Trifoliata, valor próximo ao verificado durante o experimento.

Em todos os tratamentos avaliados, foram obtidas porcentagens finais elevadas de plantas emergidas, que variaram de 88,7 a 99,7\% (Tabela 1). Além das condições adequadas para a germinação, esse resultado revela a elevada qualidade das sementes utilizadas, que

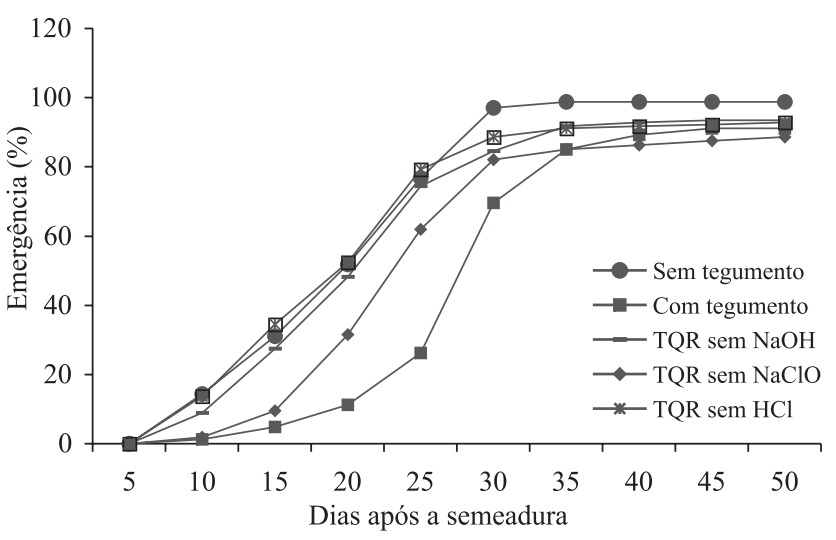

Figura 3. Emergência de plantas de Trifoliata (Poncirus trifoliata) depois da semeadura, decorrente da ausência de componentes do tratamento químico de referência das sementes.

Tabela 1. Porcentagem de plantas emergidas do porta-enxerto Trifoliata (Poncirus trifoliata) aos 15, 30 e 45 dias depois da semeadura, de acordo com o tratamento da semente.

\begin{tabular}{|c|c|c|c|}
\hline \multirow{2}{*}{$\begin{array}{l}\text { Tratamento } \\
\text { de sementes }\end{array}$} & \multicolumn{3}{|c|}{ Época de avaliação (dias) $^{(1)}$} \\
\hline & 15 & 30 & 45 \\
\hline Sem tegumento & $31 \mathrm{c}$ & $98 \mathrm{a}$ & $100 \mathrm{a}$ \\
\hline Com tegumento & $5 d$ & $70 \mathrm{~d}$ & $93 a$ \\
\hline $\mathrm{TQR}^{(2)}$ & $40 \mathrm{bc}$ & $96 a b c$ & $98 \mathrm{a}$ \\
\hline $1 / 2$ concentração TQR & $33 \mathrm{c}$ & $97 \mathrm{ab}$ & $97 \mathrm{a}$ \\
\hline $2 \times$ concentração TQR & $64 \mathrm{a}$ & $92 \mathrm{abc}$ & $96 a$ \\
\hline $4 \times$ concentração TQR & $66 a$ & $94 \mathrm{abc}$ & $96 a$ \\
\hline $1 / 2$ tempo de imersão TQR & $33 \mathrm{c}$ & $90 \mathrm{abc}$ & $94 \mathrm{a}$ \\
\hline $2 \mathrm{x}$ tempo de imersão TQR & $54 \mathrm{ab}$ & $91 \mathrm{abc}$ & $92 \mathrm{a}$ \\
\hline TQR sem $\mathrm{NaOH}$ & $27 \mathrm{c}$ & $85 \mathrm{bcd}$ & $94 a$ \\
\hline TQR sem $\mathrm{NaClO}$ & $9 \mathrm{~d}$ & $83 \mathrm{~cd}$ & $89 a$ \\
\hline TQR sem $\mathrm{HCl}$ & $34 \mathrm{c}$ & $89 \mathrm{abc}$ & $93 \mathrm{a}$ \\
\hline Média & 36 & 90 & 95 \\
\hline $\mathrm{CV}(\%)$ & 12 & 7 & 8 \\
\hline
\end{tabular}

${ }^{(1)} \mathrm{Na}$ análise estatística, os dados foram transformados para arc sen $(\mathrm{x} / 100)^{0,5}$; médias seguidas por letras iguais, nas colunas, não diferem entre si pelo teste de Tukey a $5 \%$ de probabilidade. ${ }^{(2)}$ Tratamento químico de referência: imersão de 200 g de sementes, sob agitação por 45 minutos, em solução composta por $0,5 \mathrm{~L}$ de hipoclorito de sódio $(\mathrm{NaClO})$ a $12 \%$, $3 \mathrm{~mL}$ de ácido muriático $(\mathrm{HCl})$ e $20 \mathrm{~g}$ de hidróxido de sódio comercial $(\mathrm{NaOH})$ diluídos para $2 \mathrm{~L}$ de água. 
não perderam sua viabilidade, embora tenham sido armazenadas em câmara fria por 210 dias.

O tratamento com remoção manual do tegumento promoveu maior porcentagem de emergência, relativamente ao sem remoção do tegumento. Aos 15 e 30 dias da semeadura, a emergência foi de 30,9 e 97,9\%, respectivamente, para as sementes sem tegumento, e de apenas 4,6 e 69,8\%, para as com tegumento (Tabela 1). Também a velocidade de emergência foi favorecida pela remoção do tegumento, comparativamente à sua manutenção (Figura 1). Wiltbank et al. (1995) verificaram que a germinação de sementes de Trifoliata ocorre de 9 a 84 dias, na ausência do tegumento, e de 17 a 101 dias, na presença, com porcentagem final de germinação de 100 e 81,2\%, respectivamente. Resultados similares foram relatados por Radhamani et al. (1991). O mecanismo pelo qual a remoção do tegumento acelera a germinação ainda não é bem conhecido. Segundo Soetisna et al. (1985), além do fato de acelerar a embebição, pode haver alguma substância química, presente no tegumento, que iniba a germinação.

Verifica-se que o padrão temporal de emergência proporcionado pelo tratamento que recebeu escarificação química, em dose correspondente a quatro vezes a do TQR, foi semelhante ao do tratamento com remoção manual do tegumento. Há grande similaridade no padrão temporal de emergência das plantas provenientes dos tratamentos com escarificação química, nas concentrações de meia, uma vez e duas vezes a dose TQR, cuja velocidade de emergência foi superior à do tratamento com tegumento íntegro (Figura 1).
A comparação dos padrões temporais de emergência relativos aos tratamentos com variação no período em que houve tratamento químico de referência mostra que a duplicação do tempo de imersão das sementes promoveu aumento da velocidade de emergência das plantas, sugerindo a necessidade de ajustes em sua concentração para favorecer a germinação de Trifoliata. Mesmo o tratamento com o uso de metade do tempo do TQR, cujo desempenho é inferior ao dos com maior tempo, foi superior ao tratamento com tegumento íntegro da semente (Figura 2).

Com relação à constituição do tratamento químico da semente, verifica-se, pela comparação dos padrões temporais de emergência, que o hipoclorito de sódio é o componente crítico para a eficiência do tratamento químico; sua omissão reduz sensivelmente a velocidade de emergência das sementes de Trifoliata, relativamente à omissão dos demais componentes da solução. Porém, mesmo na ausência de hipoclorito de sódio, o tratamento químico da semente tem efeito superior ao da manutenção do tegumento íntegro (Figura 3).

Aos 65 dias depois da semeadura, quando as plantas de Trifoliata encontravam-se aptas ao transplante, verificouse que as sementes submetidas à escarificação química com duas vezes a concentração do tratamento químico de referência resultaram em porta-enxertos com maiores altura (15,2 cm), diâmetro do caule (2,41 mm), produção de matéria seca da parte aérea ( 0,40 g por planta), das raízes $(0,12 \mathrm{~g}$ por planta) e total das plantas ( $0,52 \mathrm{~g}$ por planta) (Tabela 2). O desenvolvimento das plantas nesse tratamento foi superior ao daquelas obtidas com a remoção manual do tegumento, provavelmente em virtude de esse proces-

Tabela 2. Altura e diâmetro do caule, produção de matéria seca da parte aérea (MSA), das raízes (MSR) e total (MST) de plantas do porta-enxerto Trifoliata (Poncirus trifoliata), aos 65 dias depois da semeadura, de acordo com o tratamento da semente.

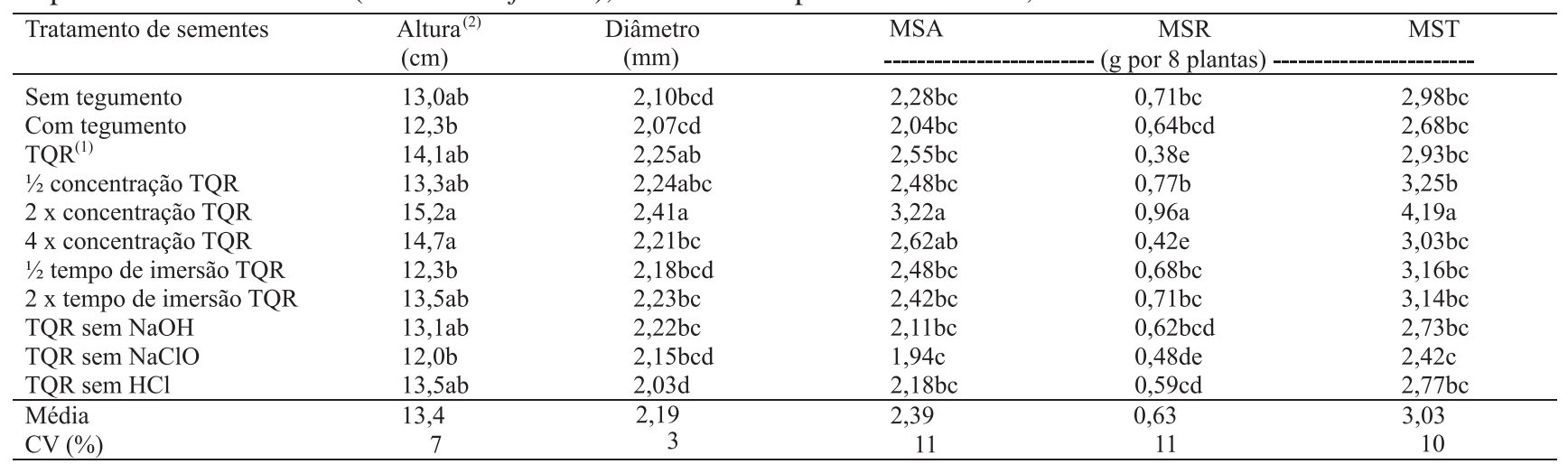

(1)Médias seguidas por letras iguais, nas colunas, não diferem entre si pelo teste de Tukey a 5\% de probabilidade. (2)Tratamento químico de referência: imersão de 200 g de sementes, sob agitação por 45 minutos, em solução composta por 0,5 L de hipoclorito de sódio (NaClO) a $12 \%$, 3 mL de ácido muriático $(\mathrm{HCl})$ e 20 g de hidróxido de sódio comercial $(\mathrm{NaOH})$ diluídos para 2 L de água. 
so causar pequenos danos mecânicos à semente (Soetisna et al., 1985).

Embora não tenham sido obtidas plantas com sintomas de toxicidade, a escarificação química com quatro vezes a dose do tratamento químico de referência afetou a produção de matéria seca das raízes ( 0,05 g por planta), que apresentou o menor desempenho entre os tratamentos estudados, devendo ter afetado a integridade das sementes. Verificou-se, também, que quanto maior a dose do tratamento químico de referência, maior a facilidade para remoção do tegumento, ao se esfregar as sementes umas sobre as outras, no interior de um pano úmido. O próprio tratamento químico provocava o início do processo de embebição e, portanto, de germinação.

Além dos resultados positivos na germinação e no crescimento das plantas de Trifoliata, os tratamentos de escarificação química das sementes, independentemente da dose e do tempo utilizados, são de fácil e rápido preparo e aplicação e, de baixo custo, em relação à extração manual do tegumento, operação que requer excessiva mão-de-obra (Oliveira \& Scivittaro, 2003). Por isso, a escarificação química é aplicável à produção em larga escala de porta-enxertos de Trifoliata.

\section{Conclusões}

1. A remoção manual do tegumento e a escarificação química das sementes de Trifoliata aumentam a velocidade de emergência e o crescimento inicial de plantas.

2. O hipoclorito de sódio é o principal componente da solução para a escarificação química das sementes de Trifoliata, potencializando seu efeito.

\section{Agradecimentos}

Á Fapergs e ao CNPq, pelo financiamento do projeto e pela concessão de bolsas.

\section{Referências}

ANUÁRIO brasileiro da fruticultura 2005. Santa Cruz do Sul: Gazeta Santa Cruz, 2005. 136p.

ARAÚJO, E.F.; ARAÚJO, R.F.; SILVA, R.F. da; GOMES, J.M. Avaliação de diferentes métodos de escarificação das sementes e dos frutos de Stylosanthes viscosa Sw. Revista Brasileira de Sementes, v.22, p.18-22, 2000.

LARANJEIRA, F.F.; AMORIN, L.; BERGAMIN FILHO, A.; AGUILAR-VILDOSO, C.I.; COLETTA FILHO, H. della. Fungos, procariotos e doenças abióticas. In: MATTOS JUNIOR, D.; DE NEGRI, J.D.; PIO, R.M.; POMPEU JUNIOR, J. (Ed.). Citros. Campinas: IAC; Fundag, 2005. p.511-566.

OLIVEIRA, R.P. de; SCIVITTARO, W.B. Infra-estrutura e custo de produção de mudas certificadas de citros. Pelotas: Embrapa Clima Temperado, 2004. 27p. (Embrapa Clima Temperado. Documentos, 118).

OLIVEIRA, R.P. de; SCIVITTARO, W.B. Normas e padrões para produção de mudas certificadas de citros em parceria com a Embrapa. Pelotas: Embrapa Clima Temperado, 2003. 18p. (Embrapa Clima Temperado. Documentos, 114).

OLIVEIRA, R.P. de; SCIVITTARO, W.B.; RADMANN, E.B. Procedimentos para o armazenamento de sementes de Poncirus trifoliata (L.) Raf. Revista Brasileira de Fruticultura, v.25, p.461463, 2003.

RADHAMANI, J.; MALIK, S.K.; CHANDEL, K.P.S. Seed-coat characteristics in relation to the physiology of seed-germination in Citrus and its allied genus. Seed Science and Technology, v.19, p.611-621, 1991.

ROUSE, R.E. Optimum temperatures for germinating citrus seeds. Proceedings of the Interamerican Society for Tropical Horticulture, v.41, p.136-139, 1997.

SOETISNA, U.; KING, M.W.; ROBERTS, E.H. Germination test recommendations for estimating the viability of moist or dry seeds of lemon (Citrus limon) and lime (C. aurantifolia). Seed Science and Technology, v.13, p.87-110, 1985.

WILTBANK, W.J.; ROUSE, R.E.; KHOI, L.N. Influence of temperature on citrus rootstock seed emergence. Proceedings of the Florida State Horticultural Society, v.108, p.137-139, 1995.

Recebido em 3 de outubro de 2005 e aprovado em 20 de janeiro de 2006 